\title{
Heat Transfer Due To Impinging Flames on Plane Surfaces
}

\author{
Satyananda Tripathy ${ }^{1}$, Dr. Akshaya Ku. Rout ${ }^{2} \&$ Prof (Dr.) Manmatha K. Roul ${ }^{3}$ \\ ${ }^{I}$ Research scholar, School of Mechanical Engineering, KIIT University, Bhubaneswar, Odisha, India. \\ ${ }^{2}$ School of Mechanical Engineering, KIIT University, Bhubaneswar, Odisha, India. \\ ${ }^{3}$ Department of Mechanical Engg, Gandhi Institute for Technological Advancement(GITA), Bhubaneswar.
}

\begin{abstract}
A theoretical model of both premixed and diffusion turbulent flames impinging normally and obliquely on plane surfaces have been developed. It is based on the equations for conservation of mass, momentum and energy. Methane and air have been considered as fuel and oxidizer respectively. The RNG $k-\varepsilon$ model has been used to compute the turbulence, and the Discrete Ordinate model has been used for radiative transfer in the flame. Regarding heat transfer characteristics of flame impingement, parametric studies have been made to predict the plate heat flux distribution and average Nusselt number $\bar{N} u$ as functions of jet Reynolds number, ratio of plate separation distance to nozzle diameter $(H / d)$ and equivalence ratio $(E R)$. Plate surface heat flux attains a maximum value at a location little away from stagnation point and then decreases gradually with the radial distance from the plate centre. With an increase in the value of separation distance of the plate from the nozzle, the peak in the local heat flux comes closer to the stagnation point. The average Nusselt number $\bar{N} u$ over the plate increases with an increase in Re and ER and a decrease in H/d for both premixed and diffusion flames.
\end{abstract}

Keywords: Premixed flame, Diffusion flame, Heat transfer, Nusselt number, Reynolds number.

\section{Introduction}

Direct gas flame impingement heating using hydrocarbon-air flame is employed in a wide range of industrial heating processes because of rapid and high heating rates. These include shaping of glasses, heating water walls in a boiler furnace, heating metal bars and billets, melting of scrap materials. The major disadvantage of flame impingement heating is the non uniformity of the heat flux near the stagnation point. The heat transfer due to the impingement of a flame on a target solid surface depends upon the flame structure, the temperature field in the near vicinity of the plate and both convective and radiative properties of the constituent species of the flame. The flame temperature is influenced by the flow field of the impinging jet which comprises three characteristic regions, namely, free jet region, stagnation region and wall jet region (Fig. 1). In the free jet region, the shear driven interaction of the exiting jet and the ambient produces entrainment of mass, momentum and energy which results in an expansion of the jet with the development of a non uniform velocity profile within the jet. The stagnation region is characterized by the pressure gradients which suppress the flow in the axial direction and turn it radially outward. In this region, the static pressure exceeds the ambient pressure. The static pressure distribution around the impinging surface is used to determine the extent of the stagnation region. The wall jet region is free from gradients of mean pressure and it is typically a boundary layer flow past the target surface. The flow issuing from a nozzle is either laminar or turbulent depending upon the nozzle type and the jet Reynolds number.

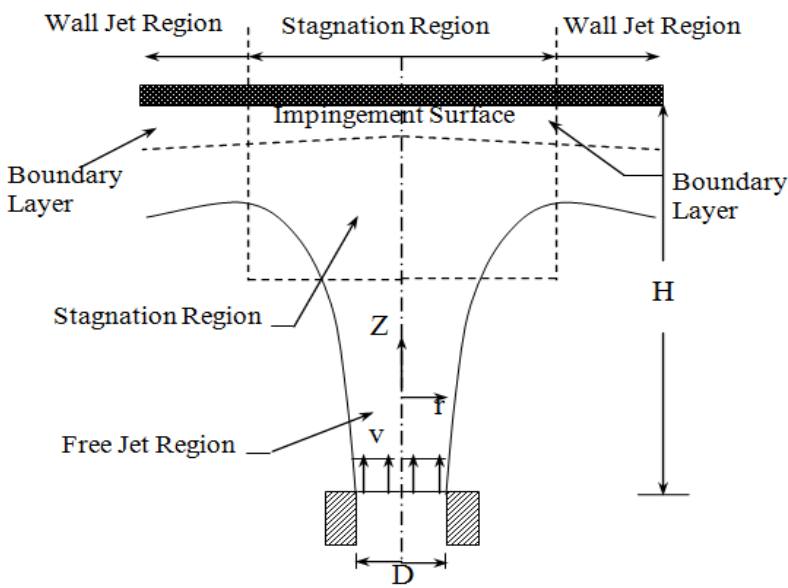

Figure 1 Flow regions for an impinging free-surface jet 
A considerable amount of research work has already been carried out in the field of flame impingement heat transfer for the last two to three decades, and a host of articles [1-3]is available in the literature today. Most of the works done in the field are of experimental in nature and report mainly the local and average heat flux characteristics of hydrocarbon-air flames impinging normal to plane surfaces for different operating parameters like jet Reynolds number, equivalence ratio, and plate separation distance. The most important works in this field are due to Baukal and Gebhart [1], Dong et al. [2], and many others. The major conclusions drawn from these works are that the plate surface heat flux distribution is non-uniform, and the maximum value of heat flux isshifted a bitaway from the stagnation point. The location of the maximum heat flux depends upon the structure of the flame which in turn is influenced by the operating conditions. Dong et al. [2] developed an empirical correlation of average Nusselt number over plate surface with jet Reynolds number, the ratio of separation distance to burner diameter and equivalence ratio. The experimental works pertain mostly to laminar flow and furnish the information that the average heat flux at plate surface increases with an increase in Reynolds number and a decrease in the ratio of separation distance to burner diameter.

The theoretical studies in flame impingement heat transfer are relatively few in number [6-7]. Most of them deal with laminar and turbulent premixed flames impinging normally to a flat surface and predict the temperature field, velocity field and heat release rate near the plate surface. Malikovet al.[6] predicted that the radiative heat flux at the plate surface is only $1 / 3$ of the total flux, while the remaining $2 / 3$ is due to the convection heat transfer from the hot jet impinging on the surface. All the works predict a non uniform temperature distribution near the plate surface with a maximum one shifted away from the stagnation point. ). Plate surface heat flux attains a maximum value at a location little away from stagnation point and then decreases gradually with the radial distance from the plate centre. With an increase in the value of separation distance of the plate from the nozzle, the peak in the local heat flux comes closer to the stagnation point.

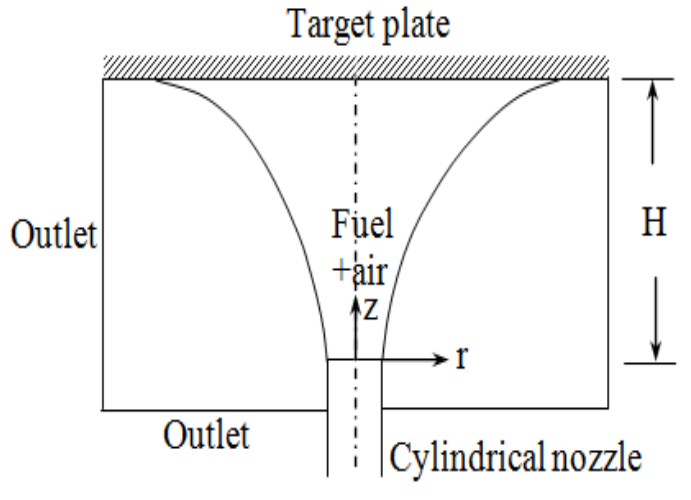

(a) Premixed flame

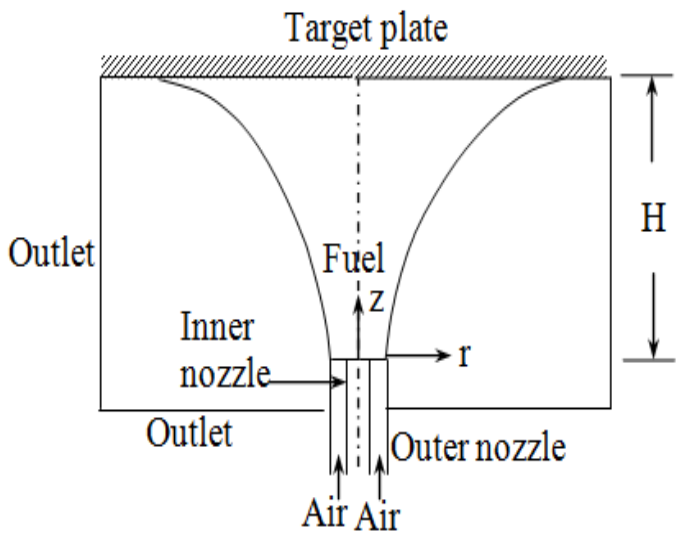

(b) Diffusion flame

Figure 2 Physical model of normal impingement

The flame/target configuration is chosen in an open cold air ambience. In principle the physical phenomenon remains unaltered with a choice of the ambient conditions to be different from open cold atmosphere (instead of a hot, near- adiabatic furnace enclosure). This is because of the fact that the fundamental mechanism of momentum and energy transfer will remain unaltered in the process. However we have chosen the ambient as an open cold air atmosphere, so as to obtain a conservative estimate of the second law efficiency, which is critically important for an efficient thermal system design.

\section{Numerical Solution}

The conservation equations of mass, momentum, Energy, turbulent kinetic energy, dissipation rate of turbulent kinetic energy, Species conservation were solved by employing a fully time implicit finite volume technique. The equations were written in a cylindrical coordinate system with proper matching of the geometry of target plates as one of the boundaries. A coupling between pressure and velocity was accomplished by using the SIMPLE algorithm. The spatial derivatives in the diffusion terms were discretized by second order central difference scheme, whereas the advection terms were discretized by first order upwind scheme. A variable size adaptive grid system was considered and variations in the size of grid were affected smoothly, with more densely-spaced grids being skewed close to the target plate. The convergence criterion for the relative errors in all the discretized equations (except the energy equation) was set to $10^{-3}$, whereas for the energy equation it was $10^{-6}$. Typically, $100(\mathrm{r}) \times 40(\mathrm{z})$ grid systems were chosen to discretize of $H / d$ ratio as $4: 1$, with proportionate enhancements in the number of grid points along $z$ for higher aspect ratios. An optimal size distribution of the 
numerical mesh to be used, for a given value of $H / d$, was determined from several numerical experiments, which showed that further refinements in grids in either directions did not change the results (maximum change in velocity or any scalar variable) by more than $2 \%$. The following assumptions have been made in the present work:

1. The flow is turbulent but steady (based on time mean values of flow parameters).

2. The oxidation of methane has been considered by global two-step irreversible reactions with finite rate chemistry.

3. The gas phase comprising air and products of combustion is assumed to obey the ideal gas laws.

4. The flow at the outlet of the burner nozzle is considered to be in a plug flow mode i.e. the discharge velocity is uniform.

5. The system is assumed to be grey absorbing, emitting medium with respect to radiation characteristics.

\subsection{Plane Circular Target Plate Normal to Flame Jet Axis}

\section{Results And Discussion}

\subsubsection{Premixed Flame Jet}

Fig. 3.1(a) shows the radial distribution of heat flux at the target plate for different values of $\mathrm{H} / \mathrm{d}$ under a given situation of $\mathrm{Re}=6000$ and $\mathrm{ER}=1$. It is observed that the surface heat flux attains a maximum value a little away from the stagnation point and then decreases gradually with an increase in the radial distance from the centre of the plate. The heat flux distribution on a target plate by flame impingement is influenced by the shape of the flame and the radial temperature distribution in the near vicinity of plate which, in turn, depend upon the burner geometry, jet Reynolds number and the position of target plate relative to the burner. At $R e=6000$, the flame is expected to be a fully developed turbulent one with an irregular wrinkled appearance. When the target plate is relatively closer to the burner with the distance of separation being less than the flame length, the flame gets deflected in the radial direction with spreading of reaction zone on the plate. With an increase in the value of $\mathrm{H} / \mathrm{d}$, the peak in the plate heat flux distribution comes closer to the stagnation point (Fig. 3.1(a)). There is an increase in the heat flux at the plate surface at all radial locations for a decrease in the value of $\mathrm{H} / \mathrm{d}$ from 15 to 8 . However, a further decrease inH/d from 8 to 4 does not reveal the similar picture. For $\mathrm{H} / \mathrm{d}=4$, the heat flux near the stagnation region including the peak heat flux is lower as compared to that for $\mathrm{H} / \mathrm{d}=8$. At higher values of $\mathrm{r} / \mathrm{d}$, the plate heat flux for $\mathrm{H} / \mathrm{d}=4$ is marginally higher from that for $\mathrm{H} / \mathrm{d}=8$. This is attributed to the radial spreading of flame and its shape due to the presence of the target plate. For both $\mathrm{H} / \mathrm{d}=4$ and 8 , the flame appears to be plate stabilized annular flame with an unreacted cool central core (Fig. 3.2(a) and 3.2(b)). This core extends upto a distance very close to plate surface in case of $\mathrm{H} / \mathrm{d}=4$. This results in a relatively high temperature one in the stagnation region adjacent to the plate surface in case of $\mathrm{H} / \mathrm{d}=8$. For $\mathrm{H} / \mathrm{d}=15$, the flame appears (Fig. 3.2(c)) almost like a nozzle stabilized envelop flame being deflected by the target plate.

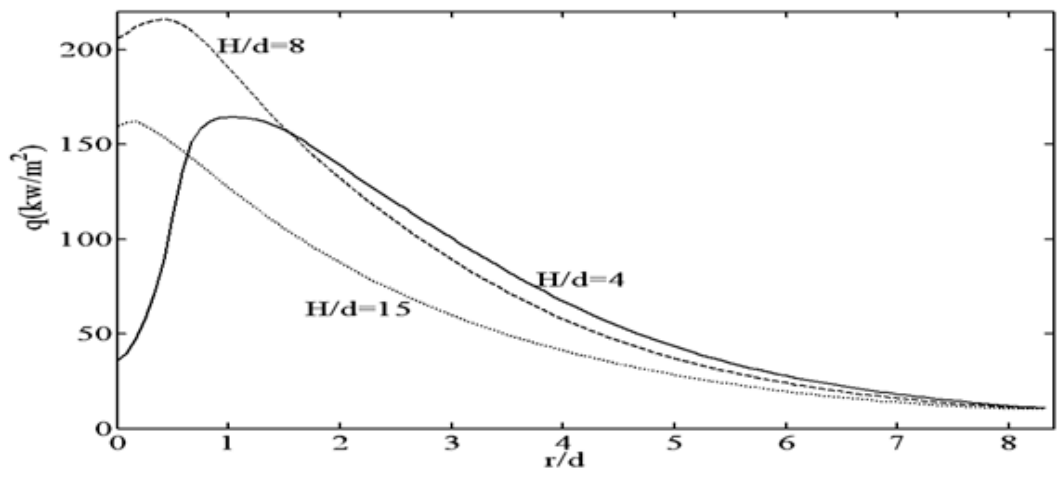

(a) $\mathrm{Re}=6000$

Figure 3.1 Local heat flux distributions on a plane circular target plate normal to flame jet axis in a premixed flame for different values of plate separation distance and jet Reynolds number $(E R=1)$.

Under this situation, there exists a short unreacted burner attached cool conical core which is engulfed like an umbrella by a high temperature flame zone that extends almost upto the plate surface. For higher values of $\mathrm{H} / \mathrm{d}$, the flame temperature is reduced due to the entrainment of more air from the surrounding. It is observed that the qualitative trend of plate heat flux distribution at a higher value of $\mathrm{Re}=10000$ (Fig. 3.1(b)) is same as that at $\mathrm{Re}=6000$, but with a difference that the heat flux in stagnation region for $\mathrm{H} / \mathrm{d}=15$ is relatively increased with the peak value being close to that for $\mathrm{H} / \mathrm{d}=8$. This can be attributed to an increase in flame length with Reynolds number. 


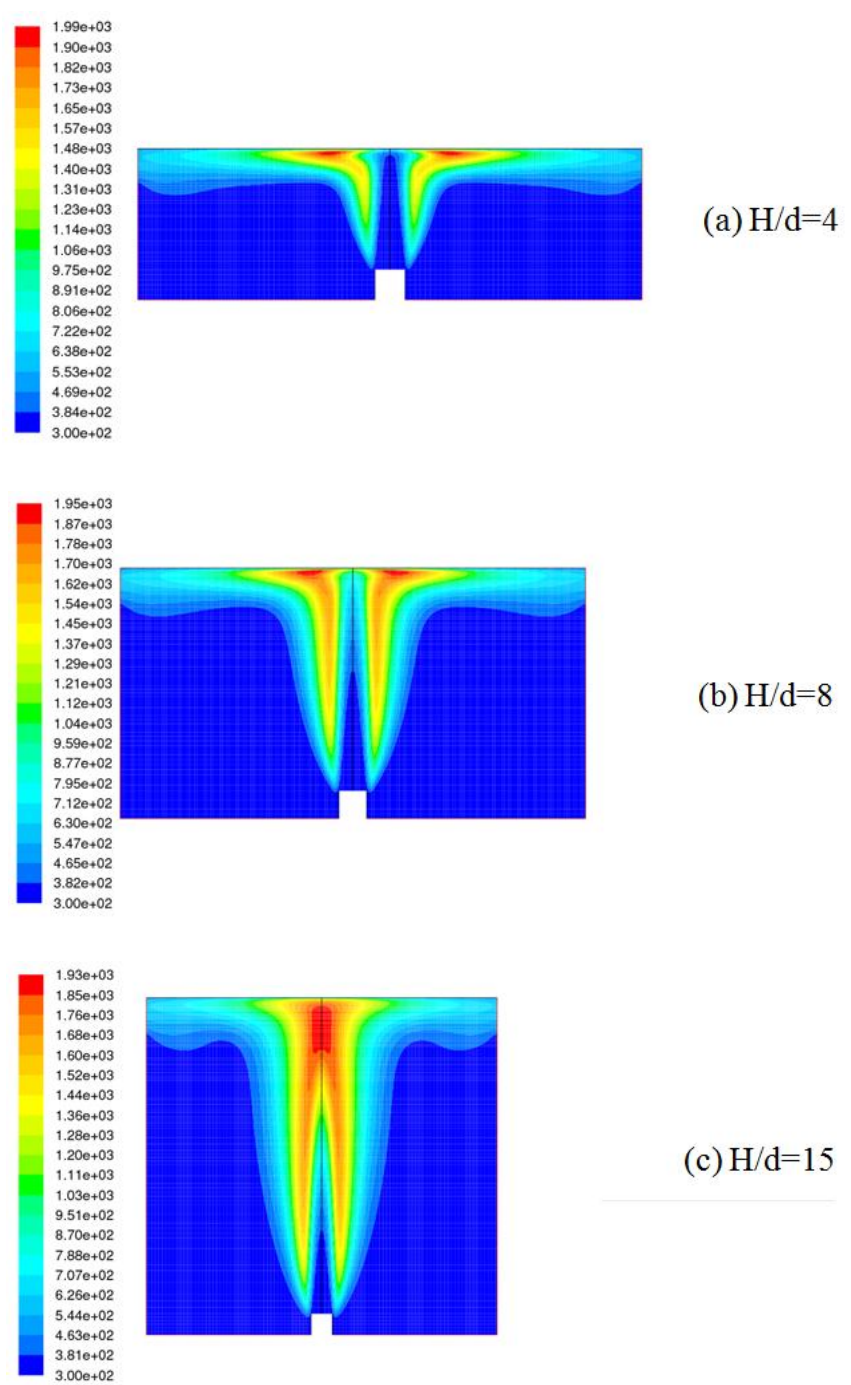

Figure 3.2 Gas phase temperature fields for premixed flames for different plate separation distances, (ER=1, $\mathrm{Re}=6000$ ).

(Temperature scales are in $\mathrm{K}$ )

The Figures 3.3(a) and 3.3(b) show the heat flux distributions at the plate for different values of separation distance $\mathrm{H} / \mathrm{d}$ and equivalence ratio ER. It is observed that local heat flux at any radial location of the plate for all values of $\mathrm{H} / \mathrm{d}$ is slightly increased with an increase in equivalence ratio ER. It is interesting to note that for a highly fuel rich mixture $(E R=2)$, the plate heat flux for $\mathrm{H} / \mathrm{d}=15$ increases substantially with the peak value being close to that for $\mathrm{H} / \mathrm{d}=8$ (Fig. 3.3(b)). This can be explained due to the fact that for a fuel rich premixed jet, the air diffused from surrounding atmosphere creates an ignitable stoichiometric combustible mixture which results in an outer diffusion flame close to the plate surface kept at a large separation distance.

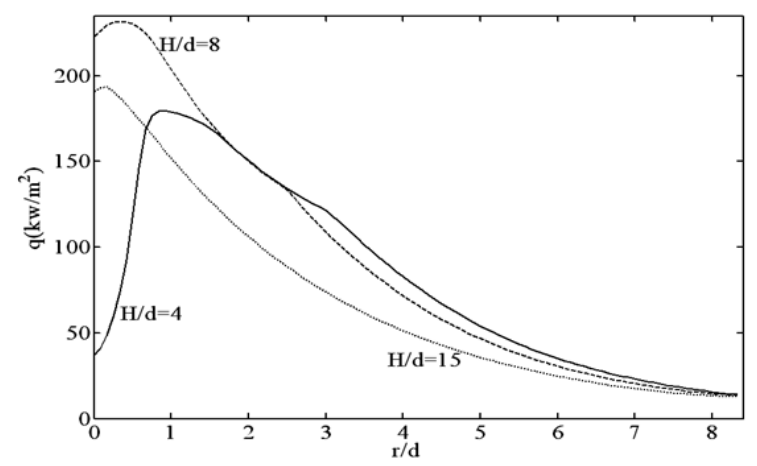

(a) $\mathrm{ER}=1.2$ 


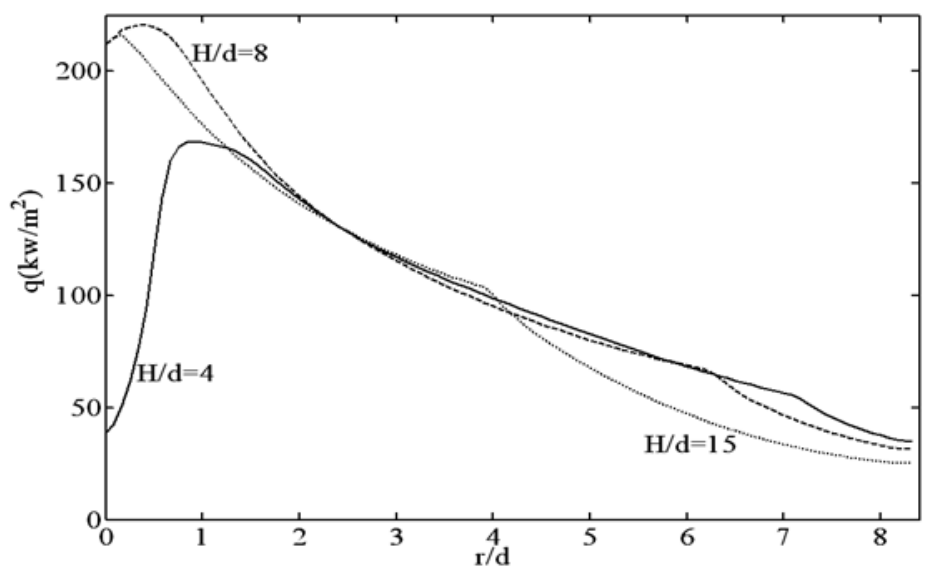

(b) $\mathrm{ER}=2.0$

Figure 3.3 Local heat flux distributions on a plane circular target plate normal to flame jet axis in premixed flames for different values of equivalence ratio $(\mathrm{Re}=6000)$

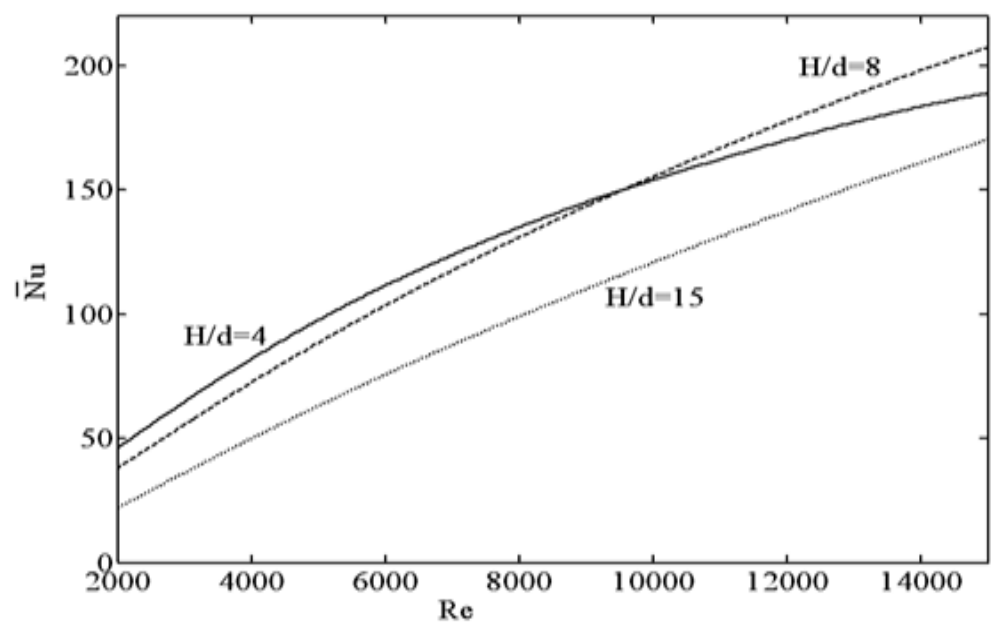

Figure 3.4 Variations of $\bar{N} u$ with Re and H/d in premixed flames (ER=1).

The variations in average Nusselt number $\bar{N} u$ over the plate with jet Reynolds number and for different values of $\mathrm{H} / \mathrm{d}$ are shown in Figures 3.4 . It is observed that the average Nusseltnumber increases with an increase in Re. When the plate is close to burner $(\mathrm{H} / \mathrm{d}=4)$, the flame is mostly attached to the plate at all Reynolds numbers. An increase in Reynolds number, under the situation, brings about a greater convective effect in reducing both the hydrodynamic and thermal boundary layer for flow of hot gases past the plate surface. This results in an increase in the rate of heat transfer. When the plate is kept at a larger distance from the burner, the flame is usually attached to nozzle rim. With an increase in Re, the flame length gets increased and the high temperature reaction zone comes closer to the plate resulting in an enhanced overall heat transfer.It is observed from Fig. 3.4 that the total heat flux from the plate for $\mathrm{H} / \mathrm{d}=4$ is more than that from the plate for $\mathrm{H} / \mathrm{d}=8$ upto a Reynolds number of 10000 , beyond which the trend is reversed. The reason for this lies in the variations of typical flame shape and the resulting heat flux distribution at the plate surface for different values of $\mathrm{Re}$ and $\mathrm{H} / \mathrm{d}$ as explained earlier.

The figure 3.5 depicts that an increase in equivalence ratio ER increases the total heat flux at all values of Reynolds number Re. The increase is more prominent for $E R=2$ and at higher values of Re. This is attributed to the burning of a stoichiometric combustible mixture close to the plate surface due to diffusion of air from the surrounding atmosphere.

\subsubsection{Diffusion Flame Jet}

The figures 3.6(a) and 3.6(b) show the heat flux distributions at the plate surface for different values of $\mathrm{H} / \mathrm{d}$ for an equivalence ratio of 1 (based on air flow through annular nozzle), and fuel jet Reynolds number of 6000 and 10000 respectively. The qualitative trends of heat flux distributions are almost the same as compared to those observed in case of premixed flame. The main differences in the results with those of premixed flames 
are that the plate heat flux at any radial location for a given value of $\mathrm{H} / \mathrm{d}$ is higher in case of diffusion flames. There is a substantial increase in the heat flux witha relatively flat distribution near the stagnation region. The diffusion flame under this situation is lifted from the burner and becomes relatively thinner with a more radial spread close to the plate surface (Figures 3.7(a), 3.7(b), and 3.7(c)). With an increase in the value of Re, the flame region gets more attached to the plate surface with a relatively larger radial spread of the flame. This results in a higher heat fluxes at the plate surfaces (Fig. 3.6(b)).

It is observed from Fig. 3.8 that for a fuel rich mixture $(E R=2)$ in a diffusion flame, the plate heat flux near the stagnation region is reduced as compared to that for $E R=1$ (Fig. 3.6(a)). The local heat fluxes for $E R=2$ at radial locations away from the stagnation region are higher with a relatively flat distribution as compared to that obtained for $\mathrm{ER}=1$. The average Nusselt number $\bar{N} u$ over the plate increases with an increase in Re and a decrease in the value of H/d. The increase in average Nusselt number $\bar{N} u$ is more pronounced for a change in $\mathrm{H} / \mathrm{d}$ from 15 to 8 as compared to a change from 8 to 4 and that too in the higher range of Reynolds number.

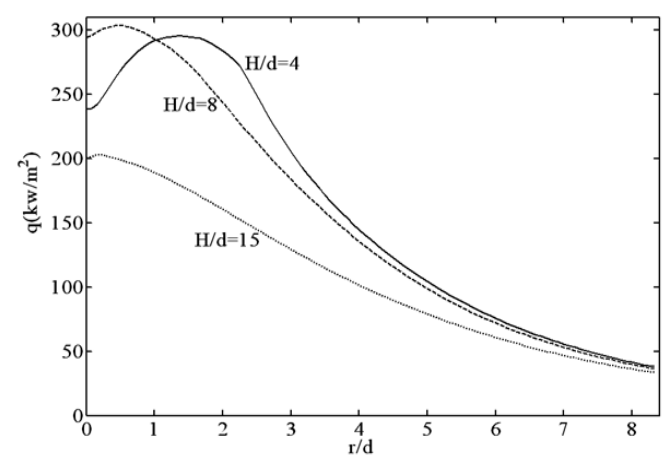

(a) $\operatorname{Re}=6000$

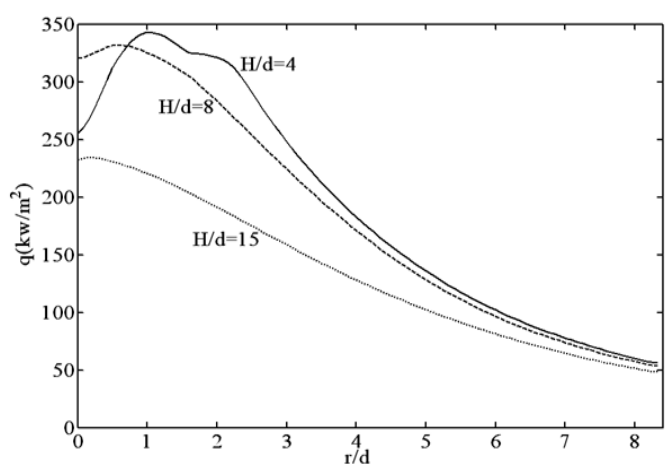

(b) $\operatorname{Re}=10000$

Figure 3.6 Local heat flux distributions on a plane circular target plate normal to flame jet axis in a diffusion flamefor different values of plate separation distance and jet Reynolds number $(\mathrm{ER}=1)$.

It is found that average Nusselt number $\bar{N} u$ increases with an increase in ER. The increase in the value of $\bar{N} u$ with ER is more pronounced at higher values of Reynolds number (above $\mathrm{Re}=6000$ ) and for a fuel rich mixture of $E R=2$. In case of $E R=2$, though the mixture is very rich near the burner, the conducive zone of burning is formed near the plate due to entrainment of surrounding air.

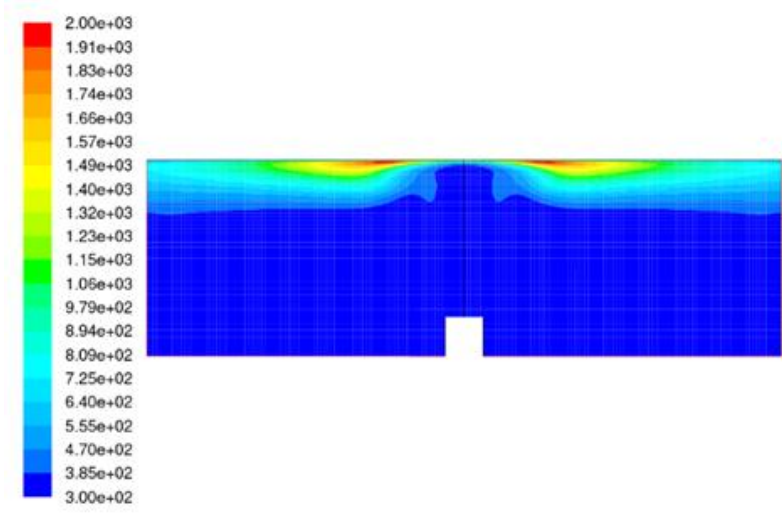

\section{(a) $\mathrm{H} / \mathrm{d}=4$}




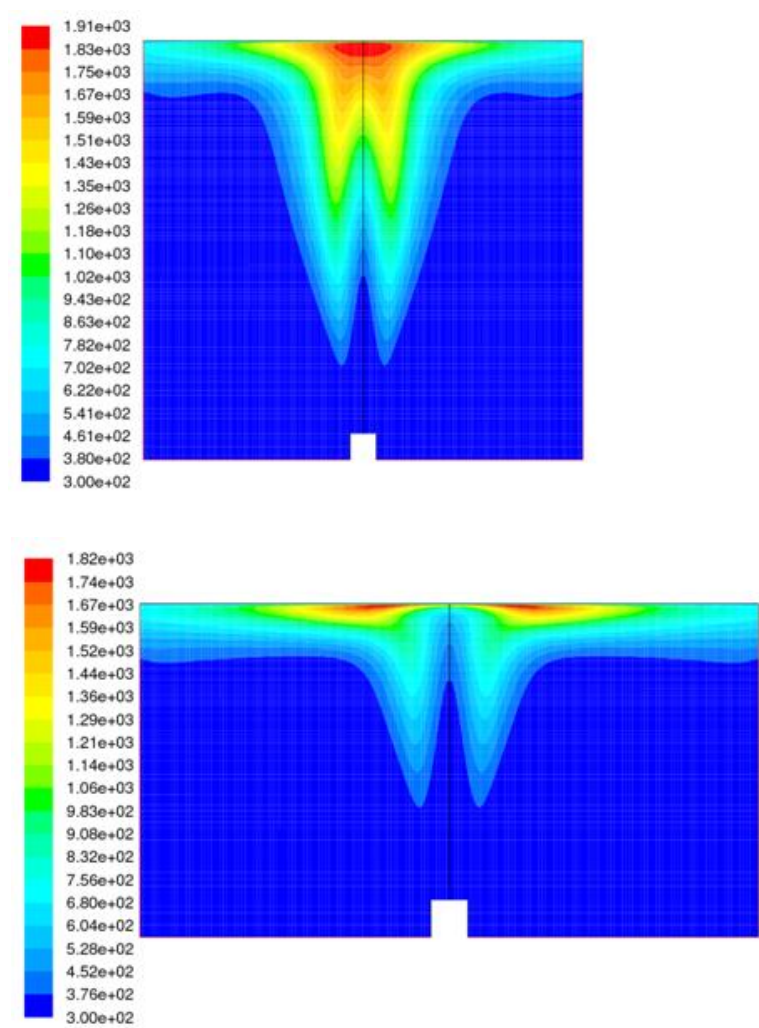

\section{(c) $\mathrm{H} / \mathrm{d}=15$}

\section{(b) $\mathrm{H} / \mathrm{d}=8$}

Figure 3.7 Gas phase temperature fields for diffusion flames for different plate separation distances, $(\mathrm{ER}=1$, $\mathrm{Re}=6000)$.

(Temperature scales are in $\mathrm{K}$ )

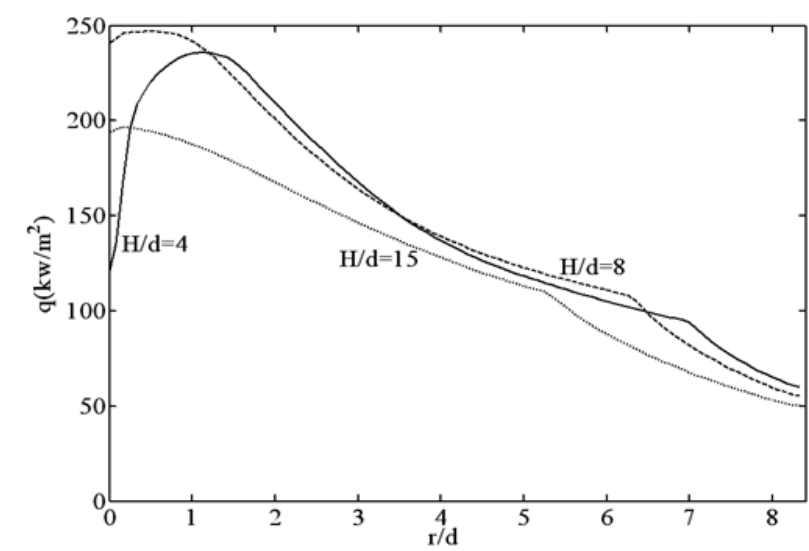

Figure 3.8 Local heat flux distribution on a plane circular target plate in a fuel rich diffusion flame, $(E R=2$,

$$
\mathrm{Re}=6000)
$$

\section{Conclusions}

The main observations of the numerical studies are as follows:

- Plate surface heat flux attains a maximum value at a location little away from stagnation point and then decreases gradually with the radial distance from the plate centre. With an increase in the value of separation distance of the plate from the nozzle, the peak in the local heat flux comes closer to the stagnation point.

- For a decrease in the value of H/d from 15 to 8, there is a substantial increase in the surface heat flux at all radial locations. However a further decrease in H/d from 8 to 4 results in a decrease in heat flux near the stagnation region including the stagnation point, but a marginal increase in the same at higher values of $\mathrm{r} / \mathrm{d}$.

- The average Nusselt number $\bar{N} u$ over the plate increases with an increase in Re and ER and a decrease in $\mathrm{H} / \mathrm{d}$ for both premixed and diffusion flames. The total heat flux on the plate is always more in case of a diffusion flame as compared to that in a premixed flame. 


\section{References}

[1]. C. E. Baukal, B. Gebhart, A review of empirical flame impingement heat transfer correlations, Int. J. Heat Fluid Flow 17 (1996) 386-396.

[2]. L. L. Dong, C. S. Cheung, C. W. Leung, Heat transfer from an impinging premixed butane/air slot flame jet, Int. J. Heat Mass Transfer 45 (2002) 979-992.

[3]. R. Viskanta, Convective and radiative flame jet impingement heat transfer, Int. J. Transport Phenomena 1 (1998) 1-15.

[4]. S. Chander, A. Ray, Flame impingement heat transfer: A review, Energy Conversion Management 46(18-19) (2005) $2803-2837$.

[5]. Z. Zhao, T. T. Wong, C. W. Leung, Impinging premixed butane/air circular laminar flame jet-influence of impingement plate on heat transfer characteristics, Int. J. Heat Mass Transfer 47(23) (2004) 5021-5031.

[6]. G. Malikov, V. Lisienko, Y. Malikov, J. Wagner, H. Kurek, Y. Chudnovsky, R. Viskanta, Mathematical modeling of direct flame impingement heat transfer, Proceedings of IMECE2006, Chicago, Illinois, USA, November 5-10, 2006.

[7]. S. V. Patankar, Numerical Heat transfer and Fluid Flow, Hemisphere Publishing Company, Washington DC, 1980.

[8]. W.M. Kays, Convective heat and mass transfer, McGraw-Hill, New York (1966)

[9]. M.J. Remie, M.F.G. Cremers, K.R.A.M. Schreel, L.P.H. de Goey, Analysis of the Heat Transfer of an Impinging Laminar Flame Jet, Int. J. Heat Mass Transfer, accepted for publication (2007).

[10]. H.Q. Yang, T. Kim, T.J. Lu, K. Ichimiya, Flow structure, wall pressure and heattransfer characteristics of impinging annular jet with/without steady swirling,Int. J. Heat Mass Transfer 53 (2010) 4092-4100. 